\title{
Aristóteles y la poética del Barroco
}

\author{
José Alsina*
}

Cuando en otoño de $1915 \mathrm{H}$. Wölfflin daba cima a su libro Kunstgeschichtliche Grundbegriffe ${ }^{1}$ remataba el prólogo de la obra con las siguientes palabras:" "Ya con el título se da a entender que no se tratan todos los conceptos histórico-artísticos; mas el libro no pertenece ante todo al número de los definitivos, sino al de los que apuntan e inician y han de ser superados lo más pronto posible por estudios especiales más profundos». El autor, que desde 1888 se había ocupado del problema de la definición «estructural» del barroco desde un punto de vista estrictamente artístico, ofrecía en su obra —-sumariamente esbozada, en sus líneas generales, en una comunicación expuesta tres años antes ante la Academia de Ciencias de Berlín - una clara delimitación de los rasgos esenciales del Barroco. Con ello prestaba un valioso servicio no sólo a la Historia del arte, sino también a la misma Ciencia de la literatura. $Y$ a pesar de que el propio Wölfflin tuvo que someter sus conclusiones a cierta revisión ${ }^{2}$, la verdad es que nadie ha dejado de reconocer, en términos generales, la importancia indiscutible del camino trazado por el eminente historiador del arte. «Con los Principios de la historia del arte de Wölfflin - ha dicho por ejemplo H. Hatzfeld ${ }^{3}$-, el Barroco queda definitivamente establecido como fenómeno estilístico con una riqueza de ejemplos convincentes para todas las artes del dibujo en la mayor parte de los países de Europa en el siglo XVII». celona.

1. Munich, 1915. Hay traducción española con el título de Conceptos fundamentales de la historia del arte, Madrid, 1952 (tercera edición).

2. Cfr. su trabajo «Kunstgeschichtliche Kunstbegriffe: Eine Revision» (Logos, XXII, 1933, 210 ss.).

3. Estudios sobre el Barroco, Madrid, 1966, 15. 
Como es bien sabido, la idea central del libro que nos ocupa consistía en la determinación de cinco pares de conceptos, cada uno de los cuales contrapone un rasgo renacentista a otro barroco. Estas categorías artísticas son: lineal frente a pictórico; superficie frente a profundidad; forma cerrada frente a forma abierta; claridad frente a oscuridad; y, finalmente, variedad frente a unidad. Tras analizar y contrastar estos cinco pares de categorías artísticas, el historiador se lanza a la empresa de definir, con principios exclusivamente artísticos, los rasgos esenciales del Barroco. Este sería, según Wölfflin, definible como la disolución de la forma plástica y lineal en algo cinético, palpitante, inaprensible. Su gran logro técnico consistiría en borrar los límites y los contornos para dar la impresión de lo ilimitado e infinito. El resultado final, la transformación del ser personalmente rígido y objetivo en un elemento «in fieri», en una función, en un intercambio entre sujeto y objeto. $O$, por decirlo con unas palabras de A. Hauser ${ }^{4}$ : «La voluntad artística del Barroco es... cinematográfica».

Muy pronto, y ello es comprensible, se intentó aplicar los métodos de Wölfflin a otros campos. No ya sólo a campos pertenecientes a la historia del arte (Weisbach, en 1921 los aplica a la iconografía), sino a otras disciplinas. Conocido es el libro de Adolfo Salazar ${ }^{5}$ que, con más o menos éxito, intentó explicar fenómenos de la historia de la música partiendo de los postulados teóricos de Wölfflin. Pero el caso más interesante, por las consecuencias que ello iba a traer, son los trabajos de Oskar Walzel. En efecto, un año después de la aparición de los Conceptos fundamentales, es decir, en 1916, aparece un interesante estudio del mencionado crítico $^{6}$ en el que, partiendo de la posibilidad teórica de una historia comparada de las artes, llega a la conclusión de que, si se aplican adecuadamente las categorías de Wölfflin a la estructura dramática de Shakespeare, este autor aparece como un hombre del Barroco. El argumento fundamental de Walzel era que la dramaturgia del inglés no responde, en su estructura, a la simetría típica de las producciones renacentistas. En otra obra suya, Walzel da un paso más: no contento con aplicar los principios wölfflinianos a un solo autor, extiende sus investigaciones a toda la literatura alemana del $\mathrm{XVII}^{7}$ a la que define como típicamente barroca. $\mathrm{Y}$ así, paulatinamente, se produce una fecunda profundización que iba a traer las más trascendentales consecuencias para una cabal comprensión

4. Historia social de la literatura y el arte, Madrid, 1957, II, 608.

5. Conceptos fundamentales de la historia de la música, Madrid, 1940.

6. "Shakespeare's dramatische Baukunst) (Jahrbuch der Shakespearegesellschaft, LII, 1916, reproducido en Das Wortkunstwerk, Leipzig, 1926).

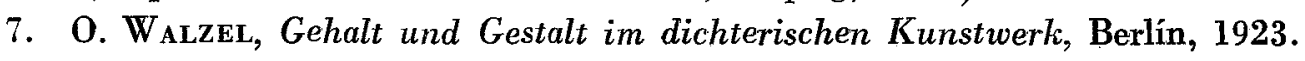


del fenómeno literario, y no sólo literario, del Barroco ${ }^{8}$ : Sitwell, Viëtor, Cysarz, Pfandl hacen a su vez valiosas contribuciones al problema.

No es aquí momento, ni tengo autoridad para ello, de someter los puntos de vista de Wölfflin a una crítica pormenorizada de sus ideas. Algunos autores han insistido, por ejemplo R. Wellek ${ }^{9}$, en que «las artes no se desarrollan con igual rapidez», hecho que, de comprobarse, reduciría un tanto la posibilidad de la aplicación de las ideas del historiador del arte. Pero esta afirmación de Wellek, que a grandes rasgos puede aceptarse, ha de someterse, a su vez, a severo análisis. Cuando afirma, por ejemplo que «la literatura parece a veces que se queda a la zaga de las artes» puede afirmarse que este «a veces» es, ciertamente, vago, y que si comparamos el arte de la época en que se componen los poemas homéricos con estos mismos poemas, comprobaremos que más bien quien se queda a la zaga es el arte: y realmente, las producciones artísticas de los siglos VIII y VII antes de Cristo no han alcanzado, ni de lejos, la perfección del poeta.

Todo eso es poco importante. Lo que es importante, para el tema que nos interesa, es el hecho de que, después del libro de Wölffin, es finalmente posible abordar la historia del arte desde un punto de vista estrictamente artístico, sin acudir, o por lo menos sin exagerar, el influjo ideológico. Y, es, sobre todo, importante porque, después del libro que nos ocupa, ha sido posible intentar una comprensión del Barroco como fenómeno unitario, hecho en el que, hoy por hoy, parecen estar prácticamente de acuerdo los especialistas en este período de la Historia: véase, si no, el interesante estudio que Hatzfeld ha dedicado al tema en el primer capítulo de sus Estudios sobre el Barroco ${ }^{10}$.

Acudiendo unas veces, como en el caso señalado de Walzel, a categorías artísticas; aplicando, otras, criterios psicológicos, como hizo A. Wellek al señalar el importante papel del color en el barroco; presentando, en otros casos, el Barroco como fenómeno típico de un país concreto, que se se difunde luego por doquier, sea el país de origen Alemania, Italia o España; buscando, en fin, la fuente del movimiento en el Concilio de Trento, como hará Bataillon: en todo caso, el hecho es que priva hoy entre los especialistas la tesis de una cierta uniformidad barroca y que pertenecen al movimiento espíritus como Corneille y Tasso, Góngora y Quevedo, Boileau y Shakespeare, Cervantes y Calderón. Si se ha distinguido la etapa

8. Señalemos que algunos de sus principios han sido aplicados a la filología clásica. Así, H. Fraenkel (Dichtung und Philosophie des frühen Griechentums, Nueva York, 1951, aplicó el concepto de (forma abierta» a la literatura griega arcaica, en oposición a la (forma cerrada) del período clásico.

9. Teoría literaria, Madrid, 1953, 231 ss.

10. (Examen crítico de las teorías del barroco», en el libro ya citado. 
manierista de la puramente barroca; si se ha intentado establecer una diferencia generacional entre barroco puro y barroquismo ${ }^{11}$, todo ello no es, en verdad, sino una profundización de las intuiciones geniales de Wölfflin.

En el marco de esos hechos, bien conocidos por otra parte de los especialistas, la intención del presente estudio es penetrar en un aspecto que, si no nuevo, bien merece una cierta profundización: me refiero a la actitud del Barroco frente al mundo antiguo, concretamente frente a Aristóteles que, barrido prácticamente por Platón en la etapa renacentista - sin, empero, ser olvidado por completo ${ }^{12}$-vuelve ahora, en el siglo XVII, a cobrar autoridad, y iqué autoridad! Nos proponemos, pues, tratar en este trabajo dos puntos básicos: de un lado, analizar las causas que determinan el acercamiento barroco al Estagirita, y, en segundo lugar, poner de relieve cómo, por una extraña paradoja, ese Aristóteles barroco estará falseado por condicionamientos ideológicos típicamente barrocos.

En realidad, según veremos, no va a tratarse tanto de adoptar al Estagirita como inspirador de la estética, sobre todo trágica, del Barroco, como de seguir los procedimientos a través de los cuales se pretende interpretar la Poética a partir de ideas completamente ajenas a su autor. En todo caso, creemos que esta aproximación permitirá a los historiadores de la literatura una mayor profundización de las perspectivas de su propio campo. Toda colaboración es siempre fértil, pero es, sobre todo, en el campo de la historia de las ideas - y no sólo estéticas- donde esa colaboración se revela más fructífera.

\section{I}

Hemos convenido en señalar que, de acuerdo con los más recientes estudios sobre el tema, domina hoy el convencimiento de que el Barroco, como etapa cultural de Occidente, ofrece una gran unidad. Podríamos decir, anticipando un tanto las cosas, que esa unidad, estética sobre todo, del Barroco, viene presidida como un estilo informado por dos obras básicas de Aristóteles: la Poética y la Retórica. Por otra parte, esa unidad puede a su vez definirse como una serie de unidades secundarias, cuyo rasgo esencial no dudaríamos en señalar: el principio de autoridad. Emile Simon ha señalado con acierto ese hecho fundamental ${ }^{13}$ al definir como elementos esencial del barroquismo, entre otros, los siguientes: una forma

11. Véase el cuadro generacional en H. HAtzFeld, «Estilos generacionales: manierismo, barroco, barroquismo" (en Estudios sobre el Barroco, 72).

12. Cfr., por ejemplo, BRuno $\mathrm{N}_{\mathrm{ARDI}}$, Saggi sull'aristotelismo padovano del secolo XIV al XVI, 1958.

13. "L'esprit du Baroque» (en Mercure de France, nov. 1, 1948, 484). 
política, el Estado absoluto; una doctrina política: la que puede obtenerse de la Biblia; una moral, contra la que protestaba Pascal; una literatura, un traje...

Hay, sobre todo, un rasgo específico que tiende a presentarse como fuente de la que brotan los demás: una actitud digamos dogmática. En el campo literario, y estético en general, ello tendrá como consecuencia primera la invocación del principio de autoridad y, como consecuencia también lógica de ese principio, la búsqueda de unas normas a las que es fuerza someterse. Pero, en segundo término, señalaremos en el Barroco una especifica actitud ante la Antigüedad, precisamente la fuente de donde van a proceder los principios estéticos en los que se inspiraron los «preceptistas».

Conviene, empero, no perder de vista que esa Antigüedad será vista a través de un prisma muy especial. Y, en efecto, el Barroco define sũ âctitud espiritual ante los antiguos a través de su especial actitud frente al período anterior, frente al Renacimiento.

Si el Renacimiento, sobre todo el Humanismo renacentista, es definible como una aproximación a los antiguos con una actitud decididamente paganizante —salvando todos los peros que se quieran-, el Barroco, concebido como una unidad estético-literaria, e incluso religiosa, significa la adopción, frente a la Antigüedad, de una actitud que está en neta contradicción con el talante renacentista. Podríamos definir esta actitud barroca con los términos de racional, estética, cerebral y crítica. El Humanismo renacentista fue emocional e ingenuo, vitalista, de corte platónico, con una visión de Platón que distingue muy poco entre el filósofo histórico y su interpretación neoplatónica. Recuérdese a Marsilio Ficino, a León Hebreo, a Pico de la Mirandola. El humanista del Renacimiento, con harta frecuencia, pretende resucitar el mundo antiguo con una actitud antihistórica, para ofrecerlo al hombre como un ideal de perfección. Intenta un paralelismo entre la revelación judaica y la vaga «revelación» del mundo pagano; en muchos casos no llega ni siquiera, en su falta de perspectiva histórica, a establecer las obligadas fronteras entre lo antiguo y lo cristiano. Erasmo, máximo exponente - si no el único- de esa extraña síntesis, llega a colocar a Sócrates en la línea de los santos: Sancte Socrates, ora pro nobis. Su ideal de la Paideia Christi sonará a los oídos del siglo siguiente, como una blasfemia.

Nada más opuesto a todo eso que la ideología del Barroco. El profesor Díaz-Plaja ha podido señalar, en un marco relativamente reducido ${ }^{14}$, que

14. El espiritu del Barroco, Barcelona, 1940, 18 y ss. 
en el Barroco español - que, por otra parte, hoy tiende a considerarse típico y original ${ }^{15}$ — se ha producido un importante cambio de perspectivas a la hora de determinar los impulsos y principios esenciales del XVII frente a los ideales del Renacimiento. No es éste el momento de ocuparnos del problema concreto, para el que nos falta, por otra parte, toda autoridad. Lo que sí importa señalar es que ahora se produce una decidida ỉnversión de valores. La lucha contra Erasmo ha determinado, y no sólo en España, una nueva actitud frente a los antiguos.

Frente a la admiración ingenua del siglo anterior por los clásicos, asistimos ahora a una actitud de crítica irónica, cuando no de clara burla. En Cervantes ${ }^{16}$, en Gracián ${ }^{17}$, por citar sólo autores bien representativos, tenemos abundantes ejemplos que los críticos se han tomado la molestia de recoger.

Sorprende, aparentemente, que frente a esta actitud general de reserva, Aristóteles goce de tanto respeto y estima ${ }^{18}$. Durante los primeros decenios del XVII asistimos a una especie de redescubrimiento de la Poética. Las razones de ese descubrimiento son, por supuesto, múltiples, y una de ellas fue, sin duda, que la oposición espiritual frente al Renacimiento valorara de nuevo a un autor que, como Aristóteles, había sido desplazado por Platón, volviendo a ocupar el puesto de honor que durante la Edad Media ocupara. Este solo hecho permite insistir en el parentesco espiritual entre Edad Media y Barroco, tal como señalara ya, entre otros, Díaz-Plaja en su Espíritu del Barroco. Pero hay aún otra razón más profunda: el sistema aristotélico-tomista —revivificado como ideal filosófico-religioso durante el siglo XVII - alcanza, con esta adopción de las ideas estéticas del Estagirita, su culminación - aunque, como veremos, esta adopción será empañada por notables deformaciones de su pensamiento. La Poética de Aristóteles, podemos afirmar con Toffanin ${ }^{19}$, llegó a ser el gran triunfo estético del Barroco, aunque ello trajo su necesaria contrapartida, pues los ideales literarios barrocos quedaron como aprisionados por ella. Si el sistema aristotélico-tomista se considera, en este momento, como la genuina objetivación de la philosophia perennis, cabe afirmar que, por razones análogas, la Poética de Aristóteles aparece a los espíritus del siglo XVII como la epifanía perfecta de la poetica perennis. Aristóteles se convierte, así, de golpe, en el símbolo indiscutible de la autoridad en litera-

15. Cfr. H. HATzFeld, «El predominio del espíritu español en la literatura europea del siglo XVII), (Rev. Fil. hisp., III, 1941, 9 y ss.).

16. Cervantes, Quijote, primera parte, prólogo.

17. El Criticón, I, 27.

18. Sobre la influencia general del aristotelismo, cfr. A. Mansion, Het Aristotelisme in het historisch perspectief, Lovaina, 1954.

19. Il Tasso e l'età fu sua, Nápoles, 1947, 12. 
tura. De ahí las ediciones, los estudios, los comentarios que de esta obra empiezan a aparecer ${ }^{20}$.

De ahí una notable consecuencia: italianos, franceses y españoles derivan de Aristóteles sus principios estéticos con una interpretación sui generis que un siglo después, por obra de Lessing, se intentará desmontar ${ }^{21}$. En esto se llega incluso a extremos que pueden parecer pueriles, pero que analizados más de cerca no lo son. Aristóteles recomienda en su Poética el uso de «adornos» ${ }^{22}$. Entre tales «adornos» está, sin duda, el llamado aparato mitológico: era, por tanto, necesario justificarlo. $\mathrm{Y}$, efectivamente, hallamos en Boileau esa justificación. Sólo que lo mitológico debe arroparse bajo el manto de cierta alegoría:

«Chaque vertu devient una divinité:

Minerva est la prudence et Venus la beauté» 23

Ahí está la puerta abierta para que el aparato mitológico, tolerado por el concilio tridentino, dé paso a lo que será lo maravilloso cristiano. Cierto que a través de una cuidada prudencia. Así, mientras los poetas renacentistas utilizan la tradicional invocación a la musa - siguiendo la pauta de los clásicos-, los poetas barrocos, sin renunciar a un procedimiento ya consagrado, van convirtiendo esa musa clásica en una figura cristianizada. Tal es, por ejemplo, el procedimiento de Tasso en el comienzo de su Gerusalemme liberata. En lugar de invocar unas fuerzas paganas que se oponen a la acción de Godofredo se alude al Infierno; en vez de presentar a una divinidad pagana protegiendo la acción del héroe, se invoca a la Virgen, pero aludida con perífrasis de corte tradicional:

Canto los piadosos combates y al guerrero que liberó el sepulcro de Cristo. En vano armóse contra él el Infierno; en vano se armaron para combatirle los pueblos del Asia y el Africa. El Cielo protegió sus esfuerzos y bajo santos estandartes recondujo a sus compañeros errantes.

¡Oh Musa! Tú que ciñes tu frente con el laurel efímero recogido en la cima del Helicón; tú que habitas en el Olimpo rodeada de coros celestiales; tú, cuyas sienes están coronadas de estrellas inmortales...

20. La más notable fue sin duda la de Dacier, La Poétique d'Aristote traduite en français avec des remarques critiques, París-Amberes, 1692.

21. Cfr. M. Kommerell, Lessing und Aristoteles, Frankfurt, 1940.

22. Poética, cap. 21-22; cfr. Aristóteles, Retórica, III, 2, 1404 b.

23. L'Art poétique, III. 
No de otro modo actúa Cervantes, aunque en nuestro escritor es de notar una no velada ironía cuando, como en el pasaje de la salida de D. Quijote, describe la aurora en términos que, sin dejar de recordar pasajes antiguos, descubren una risa burlona en sus labios: aquí tenemos «el rubicundo Apolo», «la rosada aurora», o, en otros pasajes, la «señora Diana», (Quijote, II, 68).

Por su parte Racine, el Racine enamorado de Eurípides, a quien leía y anotaba en sus textos originales, lleva a cabo una profunda revolución estética y literaria cambiando a los personajes de sus fuentes antiguas para dotarlas de unas cualidades que, según su propia expresión, hubiera exigido Aristóteles a un héroe trágico:

toutes les qualités qu'Aristote demande dans les héros de la tragédie (Phèdre, préface).

Precisamente, la gran empresa de Racine consistió, en este punto concreto, en algo que reviste una importancia de gran trascendencia: en su época, y antes, la tragedia griega no era conocida directamente, sino a través de lo que de ella dice Aristóteles en su Poética. Los poetas buscaban los personajes del drama antiguo en Séneca. Pero, por decirlo con unas palabras de VosSLeR ${ }^{24}$ «le estaba reservado a RACINE descubrir en la tragedia griega algo más que el espíritu del coro».

\section{III}

Hasta aquí no hemos hecho sino plantear los términos generales del problema: apoyados en los más modernos estudios sobre el tema hemos puesto de relieve la presencia de Aristóteles en la elaboración de los principios generales que van a presidir la poética barroca; pero, por otro lado, hemos insistido también en el proceso que tiene lugar en el Barroco y que va a conducir a la cristianización de los elementos poéticos y estéticos que definían al período inmediatamente anterior. Ahora es preciso hacer un breve alto en nuestro camino. Es conveniente detenernos un instante para analizar la esencia de la tragedia griega según su ilustre exégeta, Aristóteles, para, acto seguido, ver de aclarar cómo han sido interpretadas en el Barroco las ideas aristotélicas sobre la tragedia.

¿Qué es una tragedia según Aristóteles? En el capítulo VIII de su Poética nos ofrece el filósofo una definición : «La tragedia es la imitación de una acción elevada y completa, de cierta extensión, dotada de un lenguaje sazonado en su especie conforme a sus diversas partes, ejecutada

24. K. Vosslen, Racine (trad. cast.), Madrid-Buenos Aires, 1946, 114 ss. 
por personas en acción y no por medio de relato, y que, por obra de la compasión y el temor lleva a término la purgación de tales pasiones». Y añade más adelante que en toda tragedia lo esencial es el paso de una situación feliz a otra desgraciada, y que en ese cambio un ser noble, por causa de la «hamartía», pasa de un estado dichoso a otro infeliz.

Esa sencilla definición, al menos sencilla en apariencia, ha provocado un auténtico alud de estudios y comentarios. Qué sea mímesis, qué debe entenderse por compasión (éleos) y por temor (phóbos); qué sentido tiene el término metabolê (cambio); qué hay que entender por hamartía; cómo debe entenderse la expresión «purgación de tales pasiones» ${ }^{25}$. Pero de todos esos puntos, nos interesan, fundamentalmente, dos: kátharsis (purgación) y hamartía (falta, culpa).

Comencemos por la famosa kátharsis trágica. Los trabajos dedicados a interpretar el auténtico sentido que, en la obra aristotélica, tiene dicho término, son innumerables, y podríamos llevar a cabo una antología de textos sobre el tema que ocuparía un grueso volumen: comenzando por los tratadistas del Renacimiento (Rebortelli, Minturno), pasando por los franceses (BAtTeux, Chapelin), alemanes (Lessing), hasta llegar a los filólogos y eruditos del siglo pasado (BERnays, Weil) y de nuestra época (Sch adewaldt, Flas har, Po hlenz) ${ }^{26}$. La verdad es que ha habido interpretaciones para todos los gustos: Los humanistas del siglo XVI interpretaban el efecto de la kátharsis como un endurecimiento frente a las vicisitudes de la vida, como un fortalecimiento moral; los preceptistas del siglo XVII extienden la acción catártica de la tragedia a todas las pasiones, y no sólo al temor y a la compasión, como tenemos explícitamente en Aristóteles. Como tendremos ocasión de comprobar, Corneille entiende que el espectáculo trágico nos incita a moderar e incluso a desarraigar de nuestro espíritu la pasión que sume en la desgracia al protagonista de la tragedia que se nos of rece en el espectáculo trágico. A fines del siglo XVII las interpretaciones tienden a abandonar la exégesis éticopsicológica para orientarse hacia una interpretación médica. Esta nueva orientación de la crítica culmina en BERNAYs ${ }^{27}$, en pleno siglo XIX, quien rompe de un modo decidido con la exégesis tradicional, la ética, para sostener que la única solución viable para una cabal intelección de la doctrina aristotélica es la que postula que «catarsis de las pasiones no sig-

25. Una buena puesta a punto del problema, con abundante bibliografía, puede verse en P. Laín, La curación por la palabra en la Antigüedad clásica, Madrid, 1958, 2,43 ss.

26. Véase en Laín, op. cit., p. 266 , la principal bibliografía, con discusión de las tesis principales.

27. Cfr. sus Zwei Abhandlungen über die aristotelische Theorie des Dramas, Berlín, 1880. 
nifica otra cosa que una purgación del alma en el sentido más cabalmente médico de la expresión». La filología de nuestro tiempo no ha ahorrado esfuerzos para profundizar en esa tesis, $y$, tras los trabajos de Dirlmeier, Po h lenz, Schadewaldt y Laín ${ }^{28}$, podemos afirmar que se ha llegado a un acuerdo de principio en que la catarsis trágica no es de orden moral ni psicológico: Es, sencillamente, el placer que produce el espectáculo trágico, cuyo «telos» es la purgación psicosomática. $O$ por decirlo con las palabras de Pedro LAín, un historiador de la medicina perfecto conocedor del mundo clásico: «La látharsis de que nos habla Aristóteles sería, ante todo, una catarsis verval ex auditu».

Pasemos ahora al término hamartía. 'También aquí nos hallamos ante un auténtico problema, y su discusión ha hecho correr mucha tinta. Debemos a K. von Fritz ${ }^{29}$ uno de los trabajos más completos y, en cierto modo, podemos decir que definitivos, para enfocar debidamente el planteamiento del problema. Intentemos resumir sus valiosas conclusiones: Es mérito del filólogo alemán el haber sabido dar a la cuestión un planteamiento original, consistente en seguir las huellas de las causas y razones que, históricamente, han podido conducir a la tesis, de origen senequista como veremos, de que en el núcleo de todo destino trágico hay una «culpa» cuya sanción ejemplifica la pieza, y que, por ende, puede hablarse correctamente de «justicia poética».

Realiza K. von Fritz, en este contexto, un exhaustivo análisis de los pasajes de Aristóteles relativos al término hamartía, llegando a la conclusión de que ni lingüística ni conceptualmente puede sostenerse la tesis que identifica hamartía con pecado (noción, por otra parte, inexistente en la época clásica, al menos en los textos más significativos). Todo lo más que puede afirmarse es que hamartía es una especie de «error», y no simplemente de cálculo. Ha sido Séneca - que tanto ha influído en la poética del Renacimiento- quien, trasponiendo al teatro determinadas nociones estoicas que identifican pecado con la entrega a la pasión, ha sido Séneca, repito, el culpable de ese quid pro quo. El héroe de la tragedia, tal como lo entiende Aristóteles, es «inocente» (anáxios). No hay, por lo tanto, justicia poética en la tragedia griega, al menos tal como Aristóteles la ha interpretado. $\mathrm{Y}$ es esa interpretación aristotélica la que aquí nos interesa.

28. Dirlmeier, “Katharsis pathêmatôn», Hermes, 75, 1940, 81 s.; Pohlenz, Hermes, 84, 1956, 60 s.; Schadewaldt, Hermes, 83, 1955, 129 (el trabajo de PoHLENZ es una réplica al de este autor); LAín, obra citada.

29. "Tragische Schuld und poetische Gerechtigkeit in der gr. Tragödie» (Studium generales, 8, 1955, $235 \mathrm{~s} .=$ Antike und moderne Tragödie, Berlín, 1962, Cap. I). Debemos mucho a este trabajo. 
Pero si no hay justicia poética, difícilmente puede hablarse de una posibilidad teórica de cristianizar la tragedia griega. Una tragedia cristiana planteada al estilo griego carece, pues, de sentido: el Dios cristiano es amor y justicia al mismo tiempo, mientras que el dios de los paganos - por lo menos el dios de la tragedia- es un abismo oscuro al que el hombre no puede ni siquiera asomarse.

Y sin embargo, he aquí la extraña paradoja: los trágicos del Barroco, al menos en su más genuina expresión, tuvieron conciencia de seguir las huellas de la tragedia antigua al ofrecernos lo que ellos creían una congruente armonización de Aristóteles y la Biblia. En todo caso, hay dos hechos que son claros: por lo pronto, el ascetismo tan típico del Barroco convirtió la catarsis aristotélica en algo que no había sido durante la antigüedad griega. Dado que la gran preocupación barroca fue la moral, la tragedia se consideró un medio idóneo para influir en la corrección de las costumbres, en un medio para contribuir a que el hombre consiga desarraigar esas malas inclinaciones de su espíritu. Pero con una diferencia fundamental: para Aristóteles, conforme hemos señalado más arriba, la catarsis trágica tenía como objeto primordial la liberación por parte del hombre del miedo y de la compasión a través del espectáculo trágico. Para el Barroco significó el medio de liberarse de todas las pasiones, en un acicate para la práctica de la virtud.

¿Cómo se explica esa interpretación, tan radicalmente distinta de la que of recía el modelo aristotélico? Por lo pronto, en algo aparentemente sencillo: la confusión entre Aristóteles y Horacio. Hemos visto que Aristóteles, por lo menos en la interpretación que, hoy por hoy, cabe considerar como la más verosímil, excluía de la tragedia toda justicia poética, como excluía la posibilidad de un héroe culpable. El arte, la tragedia, no tiene como finalidad la perfección moral. Lo único que puede ofrecer es la liberación de dos pasiones, la compasión y el miedo. Pero ¿y Horacio?

Aut prodesse volunt aut delectare poetae, aut simul, et iucunda et idona dicere vitae

leemos en el Arte poética (vv. 333-334). La idea de deleitar y de ser útil se toma, pues, de Horacio, sin darse cuenta de que, al hacerlo, se es infiel a quien se pretende seguir, esto es, a Aristóteles. Pero esa simbiosis de utilidad y deleite está tan fuertemente unida al alma barroca, que la hallamos siempre expresada en los principales preceptistas de la época: E1 Pinciano proclama, por ejemplo, que aunque una obra literaria cause deleite, éste debe ir acompañado siempre de un efecto moral, por supuesto positivo: AlamanNi, en el prefacio de su Avarchide, afirmará que «le unità aristoteliche corrispondono colla perfezione morale»; y LA MESNADIÈre nos ofrece una definición de poesía que reza del modo siguiente:

«esa ciencia agradable que mezcla las enseñanzas con el recreo». 
Hay un autor que puede servirnos maravillosamente para ejemplificar la actitud barroca ante los efectos producidos por la tragedia. Es un perfecto representante de la tragedia de la época $\mathrm{y}$, al tiempo, autor de un par de estudios teóricos sobre el tema. Se trata de Cornerlle. En su opúsculo Sur le poème dramatique comienza CoRneille por dejar bien sentado un hecho que, en un principio, parece que contradice nuestras afirmaciones anteriores: el único fin que persigue el poeta al escribir - se refiere por supuesto al poeta trágico - no es otro que el placer que pueda derivarse de la contemplación del espectáculo. El poema dramático busca el placer (le plaisir) del espectador. Queda pues, excluída de entrada, al parecer, toda finalidad didáctica y moral. De la doble función postulada por Horacio - prodesse aut delectare - la tragedia excluye por lo tanto, la primera, la enseñanza moral. Pero en el curso de sus reflexiones, Corneille se olvida de su tesis para conceder que ello no excluye el hecho de que, bien que secundariamente, la tragedia puede asimismo «enseñar». La razón es que «il est impossible de plaire selon les regles qu'il ne s'y rencontre beaucoup d'utilité». ¿Cómo se justifica esa postura que, al menos aparentemente, contradice lo proclamado con tanto énfasis en el comienzo del opúsculo? El autor reconoce que la palabra utilidad jamás ha sido empleada por Aristóteles en ese contexto

«Il est vrai qu'Aristote dans tout son traité de la Poétique n'a jamais employé ce mot (utilité) une seule fois, qu'il attribue l'origine de la poésie au plaisir que nous prenons à voir imiter les actions des hommes... Mais il est vrai qu'Horace nous apprend que nous ne saurions plaire à tout le monde si nous n'y melons l'utile...»

La falta de lógica es aplastante: para explicar las doctrinas de Aristóteles y justificar su aplicación a la tragedia moderna, se acude a un autor latino, cuyas ideas sobre el tema son claramente opuestas al Estagirita, al menos en este punto concreto.

Pero ¿en qué puede consistir la utilidad de la tragedia? Conneille enumera varias. La más importante -y que está en franca oposición con el espíritu de la doctrina aristotélica- es que en la obra trágica la virtud debe ser premiada, el vicio flagelado. Pero ¿no habíamos quedado en que no había justicia poética en la tragedia griega? $Y$ está tan arraigada en el espíritu de Corneille esta idea - que es una auténtica obsesión barroca- que polemiza con los trágicos anteriores a él, dado que, si bien habían solido presentar a sus espectadores el vicio y la virtud, ninguno de ellos había cuidado «de faire recompenser les bonnes actions et de punir les mauvaises». En eso, pues, era un innovador. Pero sus innovaciones estaban en contra del espíritu aristotélico que pretendía representar. 
La cuarta utilidad señalada por CoRNEILlE como una de las aportaciones de la tragedia se refiere al tema de la purgación de las pasiones. Pero en este opúsculo se ocupa muy parcamente del problema. Más se detiene en otra obra Sur la tragédie. En este tratado, cuyo subtítulo reza: sur les moyens de la traiter selon le vraisemblable ou le nécessaire, CoRneILle esboza, sin citarlo apenas, el pasaje aristotélico relativo a la catarsis trágica, para sacar luego, por su cuenta, sus propias consecuencias. Para Cornerlle la pitié (el éleos aristotélico) tiene una función específica: la de establecer un lazo de simpatía entre el actor y el espectador:

«Ainsi la pitié embrasse l'intérêt de la personne que nous voyons soufrir».

El miedo, la crainte cumple, por su parte, una función parecida:

«La crainte qui la suit regarde la nôtre».

Por obra y gracia de estas dos pasiones, pues, se producen en el alma del eventual espectador determinadas reacciones de carácter digamos profiláctico :

«Cette crainte (nous porte) au désir de l'éviter, et ce desir à purger, à modérer, rectifier et même déraciner en nous la passion qui plonge à nos yeux dans ce malheur les personnes que nous plaignons».

Como podemos comprobar, se trata nuevamente de lo que cabría calificar de una «metábasis eis allo génos». Aristóteles habla de la purificación que se produce por medio del miedo y la compasión, y esa purificación nos libera, a través del espectáculo teatral, de esas mismas pasiones. Para Corneille, se trata de una purificación total del espectador.

¿Se trata de una mala intelección del griego por parte del francés? Que ha habido una interpretación abusiva, y que el pensamiento de Aristóteles no se refleja en las ideas de Conneille, es cosa evidente. Que la distorsión se haya producido de un modo inconsciente, como resultado de la influencia que el ambiente ideológico general haya podido ejercer sobre el espíritu de Corneille, es algo que, en principio, no debe descartarse. Y ello por diversas razones. Por lo pronto, el propio Corneille señala en determinados casos que no ha acabado de entender el pensamiento de Aristóteles. Al comentar la doctrina aristotélica sobre el héroe, por ejemplo, Corneille afirma que el tipo de «hombre medio» que debe encarnar el héroe trágico, ejemplificado con figuras como Edipo o Tieste, no responde exactamente a lo que él entiende por «hombre medio»:

«Aristote en donne pour éxemple Oedipe et Thyeste, en quoi véritablement je n'entends pas sa pensée». 
La afirmación es demasiado sincera como para creer que las distorsiones que ha realizado Corneille en la obra de Aristóteles sean conscientes.

Por lo demás, hay otros datos que permiten sostener esa misma tesis. Es sabido que la crítica contemporánea del poeta sometió a un duro vapuleo algunas de las obras de Corneille, sobre todo el Polyeucte, precisamente desde el punto de las doctrinas aristotélicas. DACIER, por ejemplo, sostenía nada menos que esta tragedia chocaba contra las reglas aristotélicas. La razón de DACIER es muy sencilla - y por otra parte, muy inteligente: un héroe de tragedia no podía ser perfecto. Cuánto menos un santo, un mártir. En este punto concreto, DACIER nos da muestras de haber entendido mucho mejor que el dramaturgo las ideas aristotélicas sobre la tragedia. ¿No había afirmado Aristóteles que el cambio en el destino trágico del protagonista se produce, precisamente, por una hamartía, término por el que hoy se entiende, y debe entenderse «una cierta imperfección»?

Hasta aquí la teoría de Corneille. ¿Cuál fue su praxis como poeta? ¿Hay acuerdo perfecto entre su doctrina y su aplicación al teatro?

La falta de espacio nos impide realizar un análisis exhaustivo de toda su producción dramática, y nos contentaremos con esbozar algunas ideas en torno a dos de sus piezas, no precisamente de las más insignificantes: Le Cid y Polyeucte.

Desde un punto de vista meramente externo, Le Cid presenta ciertas analogías con Las Coéforos de Esquilo. En ambos casos se trata de llevar a cabo un homicidio bajo la presión de fuertes circunstancias externas: en el caso de Esquilo, Orestes debe dar muerte a su madre por orden del dios de Delfos, para castigar la muerte de Agamenón. En el caso de Corneille es el código del honor el que impulsa a D. Rodrigo a quitar la vida al padre de Jimena. Pero aquí terminan las semejanzas. En Esquilo asistimos a una fuerte tensión anímica que coloca a Orestes en una verdadera lucha interior entre el deber filial y sus sentimientos como brazo de Apolo. En la pieza de Corneille, Rodrigo no presenta ninguna fisura interior. Convencido de la justicia de su posición, podrá afirmar tras las muerte del padre de Jimena:

«Je le ferais encore si j'avais à le faire» ( $L e C i d, \mathrm{III}, 4)$.

Una vez llevado a cabo el castigo, la actitud de los dos personajes es asimismo completamente distinta. En Esquilo, Orestes es perseguido por las Erinias, personificación de la sangre materna vertida. D. Rodrigo, en cambio, no tiene que enfrentarse con ninguna de las consecuencias «mo- 
rales» que su acción podría comportar. La propia Jimena reconoce que su padre era culpable; el rey perdona al protagonista e incluso agradece el acto que ha realizado. En suma: D. Rodrigo es un «espejo de virtudes» en el que el espectador puede aprender muchas cosas. Le Cid es, pues, una ilustración perfecta de la tesis de Corneille de que la tragedia, además de deleitar, puede aprovechar: prodesse et delectare.

En el caso de Polyeucte ya hemos tenido ocasión de comprobar que Corneille quiere ejemplificar en su personaje a un héroe dotado de todas las virtudes cristianas y que, lleno de celo por su religión, pierde la vida en aras de un ideal cristiano. La intención del autor es, pues, clara: ofrecer al espectador una figura dotada de todas las cualidades que debe poseer un santo, un mártir. A Polyeucte le falta esa «falla», esa hamartía señalada por Aristóteles y que es la causa que determina su destino trágico.

Llegamos, pues, a una conclusión evidente: al haber violentado - por las razones que fueren- las ideas básicas de Aristóteles sobre la tragedia cae todo el edificio exegético montado por el dramaturgo francés. La tragedia de Corneille está a mil leguas de distancia del modelo que se había propuesto seguir.

Pero aquí no se trataba, primordialmente, de examinar las ideas de Corneille. Se trataba de ver, en definitiva, cómo las ideas generales de una época, la del Barroco en nuestro caso, podían desvirtuar toda una perspectiva teórica. Cómo, pretendiendo resucitar las doctrinas de un crítico en concreto, en este caso Aristóteles, se llegaba a una completa falta de comprensión del mismo.

Como ocurre en muchos casos, cada época ve en los antiguos no su verdadera imagen reflejada en un espejo espiritual, sino, en cierto modo, refractada, pues en esa imagen que se elabora hay, por lo menos, tantos elementos del pretendido modelo como aportaciones propias, conscientes o no. Todo intento por entender a los antiguos produce, casi por una necesidad histórica, un verdadero espejismo. 
